\title{
Lagoa Mirim (Brasil/Uruguai): três versões turísticas de uma paisagem
}

\author{
Laguna Merín (Brasil/Uruguay): trés versiones turísticas de un paisaje \\ Lagoon Mirim (Brazil/Uruguay): three tourist versions of a landscape
}

\author{
Jaciel Gustavo Kunz ${ }^{1}$ \\ Antonio Carlos Castrogiovanni ${ }^{2}$
}

\begin{abstract}
Resumo
A paisagem é um dos principais modos pelos quais a Geografia se relaciona ao saber e ao fazer turístico, Empiricamente, têm-se o contexto da Lagoa Mirim, território compartilhado entre Brasil e o Uruguai. O objetivo geral desta pesquisa é analisar sítios de encontro da Lagoa Mirim como partes do todo que é objeto em questão, em termos turísticos e paisagísticos. Dessa, que é a maior lagoa dos países mencionados, são eleitos três recortes espaciais, que possuem semelhanças e diferenças entre si, como arranjos e sítios turísticos: Praia da Vila da Capilha, Rio Grande e Porto de Santa Vitória do Palmar (Brasil), e Balneário de Lago Merín, Cerro Largo (Uruguai). O trabalho é ancorado no paradigma da Complexidade em Morin $(2011,2015)$ e segue a metodologia das pesquisas bibliográficas e documentais. Discorre sobre conceitos de paisagem, turismo e performances, recorrendo à literatura estrangeira Anglo-saxã, da Geografia Humanista-Cultural. Cada local é considerado sítio de encontros entre sujeitos-turistas e as paisagens, que possuem suas peculiaridades, ao mesmo tempo em que se complementam como partes. A Lagoa Mirim é distinguida como objeto geográfico e semiótico de conhecimento. Ao final, derivam novos questionamentos a serem respondidos em pesquisas futuras.
\end{abstract}

Palavras-Chave: Lagoa Mirim (Brasil/Uruguai); Paisagem; Turismo; Práticas.

\section{Resumen}

El paisaje es un de los principales medios por los cuales la Geografía se involucra con los saberes y la práctica del turismo. Empiricamente, tenemos el contexto de la Laguna Merín, território compartido entre Brasil y Uruguay. El objetivo general de esta pesquisa es analisar sítios de encuentro de la Laguna Merín como partes del todo que es el objecto en cuestión, en términos turísticos y paisajísticos. De esta, que es la más grande laguna de los países mencionados, elejimos trés secciones espaciales, que poséen similaridades y diferencias entre ellos, como conjuntos/sítios turísticos: playa de la Capilha, Rio Grande, y Puerto de Santa Vitória do Palmar (Brasil), e Balneário de Lago Merín, Cerro Largo (Uruguay). Esta investigación es anclada en el paradigma de la Complexidade en Morin $(2011,2015)$ y sigue la metodología de las pesquisas bibliográficas y documentales. Habla de los conceptos de paisaje, turismo y performances, apelando a la literatura estrangeira anglo-sajona, de la Geografía Humanista-Cultural. Cada local es considerado un sítio de encuentro de los sujetos-turistas con los paisajes, y que poséen sus detalles y al mismo tiempo en que son complementarios como partes. Distinguimos la Laguna Merín como objectos geográfico y semiótico de conocimiento. Al final, se han derivadas nuevas cuestiones para seren respondidos en futuras investigaciones.

Palabras-claves: Laguna Merín (Brasil/Uruguai); Paisaje; Turismo; Prácticas.

\footnotetext{
${ }^{1}$ Bacharel e Mestre em Turismo, Doutorando em Geografia pela UFRGS. Docente no Turismo da FURG. jacielkunz@gmail.com

${ }^{2}$ Geógrafo, Mestre em Educação e Doutor em Comunicação Social pela PUCR-RS. Docente na PUC-RS e na UFRGS. castroge@ig.com.br
} 


\begin{abstract}
Landscape is one of the key means by which Geography intersects with tourism knowledge and practices. Empirically, it is drawn attention to Lagoon Mirim's context, a shared territory by Brazil and Uruguay. The main goal in this research is to analyze Lagoon Mirim's sites of encounter as parts of a whole, which corresponds to the object discussed, in terms of tourism and landscape. From that lagoon which is the largest in the mentioned countries, it is elected three spatial sections that present similarities and differences as tourist sites and arrangements: Capilha Ville's Beach, in Rio Grande, and Harbor of Santa Vitória do Palmar, and Balneário de Lago Merín, Cerro Largo (Uruguay). This paper is anchored in the Complexity paradigm, by Morin (2011, 2015), as well as it follows bibliographic and documental methodologies. It is talked about concepts of landscape, tourism, and performances, by using foreign Anglo-Saxon literature, from Cultural-Humanistic Geography. Each studied site is regarded as a site of encounter of tourists-subjects and landscapes, and they hold particulars and, at the same time, complementarities as parts. Lagoon Mirim is deemed as semiotic and geographical objects of knowledge. By the end, it is derived new questions to be answered in forthcoming research endeavors.
\end{abstract}

Keywords: Landscape; Lagoon Mirim (Brazil/Uruguay); Tourism; Practices.

\title{
1. Introdução: sítios de encontro como objetos de estudo
}

O que pode ser inferido em relação às percepções e representações das paisagens de uma Lagoa, como a Mirim, na fronteira entre Brasil e Uruguai? Que sentimentos despertam nos sujeitos que buscam e apreciam as paisagens da maior lagoa do Brasil e do Uruguai? Qual a natureza da experiência do encontro entre sujeitos e as paisagens lacustres? Há distinções em se considerando os distintos "lados" da fronteira de Estados nacionais, ou diferentes sítios de contato?

Questões como essas encaminham para o objetivo deste trabalho, que é analisar sítios de encontro da/com Lagoa Mirim como partes do todo que é objeto em questão, em termos turísticos e paisagísticos. Os sítios de encontro elegidos são recortes espaciais de uma pesquisa de doutorado, em fase de coleta de dados primários, como observações e entrevistas, e secundários, que envolvem documentação fotográfica disponível em mídia social. Na tese doutoral, este trabalho corresponde ao objetivo específico "um", que se volta à caracterização histórico-geográfica do objeto de estudo, em detalhe, das partes que o compõe, quais sejam: Praia da Vila da Capilha, RS e Porto de Santa Vitória do Palmar, RS (Brasil), e Balneário Lago Merín, Cerro Largo (Uruguai).

Este trabalho ancora-se no método da Complexidade em Edgar Morin, e seus respectivos princípios-chave, quais sejam, o circuito recursivo organizacional, o dialógico, e sobretudo, o hologramático, segundo o qual, o todo está na parte, que contém (micro)todos - e ainda, o todo é mais que a mera soma entre as partes, que são mais que o todo. Cada ponto hologramado possui a totalidade de informações do todo. Parte e todo formam um par dialógico (MORIN, 2011, 2015). Em termos dos pressupostos metodológicos propriamente 
ditos, utilizados na coleta e análise de dados, perseguimos a busca por dados bibliográficos e documentais que pudessem, uma vez organizados e articulados, constituir-se em conhecimento - que para Morin (2011) é mais que informação - acerca do objeto em estudo, em uma pesquisa de nível exploratório-descritivo.

Distintas acepções de objeto podem ser aplicadas a este trabalho. A primeira deles é a de objeto de conhecimento. O método da Complexidade se vê como resposta ao paradigma simplificador, redutor e disjuntivo, presente no paradigma cartesiano (MORIN, 2015). Segundo tal paradigma, a ciência deve operar a separação estrita entre objeto e sujeito de conhecimento. $\mathrm{Na}$ contramão, a Complexidade preconiza a indissociabilidade entre ambos (MORIN, 2011).

Neste momento, consideramos que, ao construímos um objeto empírico de/para pesquisa e produção de conhecimento geográfico e turístico (Lagoa Mirim), atuamos como sujeitos, que falam de algum lugar e possuem constituição própria e única, uma racionalidade; além disso, ao construírem o objeto, se auto-eco-organizam como sujeitos da pesquisa e do conhecimento produzido, imputando-lhe sentido. A Complexidade trata a organização dos seres, na Complexidade como dotados da capacidade de criarem e organizarem a si próprios, ao mesmo tempo em que dependem do ambiente para tal, além de influenciarem a organização do entorno. Assim, a noção de sujeito, cara às formulações morinianas, fala de um indivíduo que é auto-exo-referente, ou seja, a emergência de um sujeito está nas relações dialógicas entre autonomia e dependência. Neste trabalho, fazemos menção a sujeito para designar os pesquisadores, mas principalmente os sujeitos turísticos (BENI; MOESCH, 2017), que podem ser os turistas, a comunidade residente, ou outros agentes intervenientes.

A segunda noção é a de objeto geográfico. Para Milton Santos (2002), o espaço referese a um conjunto indissociável, solidário e contraditório, de sistemas de objetos e sistemas de ações, mediante o qual vivemos, atualmente, o meio técnico-científico-informacional. Além da forma (objetos técnicos), são elementos do espaço geográfico, a função (confere ação a um objeto), a estrutura (essência, totalidade una) e os processos. Quanto ao "objetos-ações", o ato é mais que ação, ao incluir a intencionalidade; esta, uma ligação entre sujeito (poucos são verdadeiramente sujeitos) e objeto, que se criam mutuamente; sob a ação da forma revelam-se os eventos, que reproduzem em simultâneo o próprio espaço geográfico (SANTOS, 2002). A Lagoa Mirim em si, é um objeto natural, e mediante a socialização, a técnica e a produção, forma um par indissociável com as ações dos agentes e grupos sociais, observadas ao longo dos períodos históricos. Em relação aos fluxos humanos, simbólicos e econômicos (como os do Turismo/Lazer), a Lagoa pode ser tida como um fixo, ou melhor, nela se instalam um 
conjunto de fixos, como as infraestruturas, públicas e privadas. Fixos e fluxos formam um par indissociável, quiçá dialógico, caro à teoria espacial de Milton Santos (1998).

Por fim, a terceira faceta da Lagoa Mirim é a do objeto semiótico. O termo objeto é usado pelo filósofo-cientista Charles S. Peirce, fundador da Semiótica moderna - ciência dos signos, ou uma teoria de conhecimento baseada em signos (SANTAELLA, 2012). O objeto designa o referente na tríade que forma signo, ou ainda, o que o signo significa, e que é um referente no/do mundo, embora possa ser um imaginário (CHANDLER, 2003). É o objeto que determina o signo. $\mathrm{O}$ objeto imediato é o modo pelo qual o objeto está sendo representado pelo signo, ou o que o signo representa ser (n)aquela realidade. O objeto dinâmico, corresponde à realidade, ou o objeto efetivamente trabalhado na semiose, compelindo o signo e oferecendo resistência e limites dentro dos quais a interpretação ocorre (METROROLAND, 2009). Consideramos que as paisagens da Lagoa, e a própria Lagoa, como signos, e que sendo tais, aparecem no lugar do objeto, o qual não podemos apreender por completo. Por meio da representação, nos é feita a promessa da interpretação (semiose), ou a intelecção por meio do signo paisagístico e/ou turístico.

Os critérios para a escolha e delimitação dos recortes do estudo se devem ao fato de se constituírem em pontos de contato entre os sujeitos e a paisagem lacustre - característico das praias (dois deles), segundo Tuan (2012) - constituindo-se como sítios de turismo, recreação e lazer, em maior e menor grau. Levamos em conta um número factível de locais para o estudo. Consideramos pelo menos um local no país uruguaio. Procuramos abranger a imensa Lagoa uniformemente. Os locais escolhidos são de livre acesso e permanência. Cada um deles apresenta peculiaridades sócio-históricas na conformação de seus arranjos espaciais (seção 3). Contudo, pode haver semelhanças no modo em que os sujeitos representam as paisagens, de acordo com o local ou país, ou no modo em que esses sujeitos engajam-se em práticas de lazer e/ou turísticas nos sítios em estudo.

Sítio é uma designação espacial mais genérica, algo similar a área, mas que atine ao substrato espacial material; este não se confunde com espaço geográfico (SOUZA, 2013), ainda sim, um recorte espacial de área. Em espanhol, sítios são lugares; mas aqui, não se está abordando-os como lugares de identidade ou pertencimento e/ou de topofilia (TUAN, 2012). Sítio urbano, por exemplo, é a área onde uma cidade foi construída, não se confundindo com situação urbana. O termo "sítio" é tradução do termo inglês site, que além de sítio, pode ser aproximado com local. Porém, à diferença de sítio, local pode ser uma escala espacial de análise ou ação (SOUZA, 2013), o que se encontra fora do escopo deste estudo. 
A ideia de encontros, no turismo, é proposta por David Crouch (CROUCH, 1999; CROUCH; ARONSSON; WAHLSTRÖM, 2001). O turismo/lazer é marcado por encontros de sujeitos entre si, e entre esses e o espaço, os lugares e a paisagem. Esta pode ser vista como um flerte com o espaço, em sua poética expressiva, conectando representações e práticas (CROUCH, 2010). Por meio desse flerte, os sujeitos fundam uma relação recíproca entre o self e o objeto (WYLIE, 2014). Os encontros levam em conta o que o turista faz (ou pratica), e como o turista significa o que ele vê ou faz, como um sujeito ativo e corporificado. Essa abordagem provê uma interpretação do turismo com mais nuances do encontro complexo entre sujeitos e espaço/lugar/paisagem, em que o turismo é construído pela prática do turista. Campos de pesquisa também são sítios de encontro! (CROUCH; ARONSSON; WAHLSTRÖM, 2001).

Para Crouch (1999), os encontros não são meramente experiências de consumo, mas sim, prática ativa dos sujeitos, uma vez que o turismo/lazer envolvem engajamentos, relações e negociações. Tais encontros condensam contexto, representação e prática corporificada, e são cada vez mais esteticizados, podendo se tornar menos funcionais. Crouch (1999) prefere fazer uso conjunto dos termos turismo/lazer, que, em vez de separados, são fenômenos imbricados, meios de praticar o espaço. Aqui são importantes as chamadas geografias vernaculares, em que há (re)conexão dos diferentes domínios do conhecimento geográfico, levando também em conta os sujeitos corporificados que conhecem o mundo, de maneira participativa (CROUCH, 1999).

A paisagem figura como um dos conceitos-chave da pesquisa socioespacial (SOUZA, 2013), embora não seja monopolizado pela Geografia Cultural (MATLESS, 2003), ramo da ciência geográfica ao qual ora nos filiamos. A noção de paisagem é mais antiga que a de ambiente (de ordem ecológica); possui origem artística e merece análise estética (ROGER, 2008), entre outras. Paisagens e outras representações do espaço são as mais fundamentais expressões da espacialidade humana (CORRÊA, 2011). Adquirem centralidade para a Geografia, ao denotarem o modo como esta é vista, imagetizada e imaginada (COSGROVE, 2002). A experiência da paisagem consiste “[...] em selecionar, enquadrar, composto o que é visto; em outras palavras, o observador exercita um poder imaginativo de transformar o espaço material em paisagem.” (COSGROVE, 2002, p. 254). Espaço geográfico é a categoria central da ciência geográfica, e a paisagem, um de seus conceitos, possuindo suas próprias possibilidades analíticas e interpretativas; assim, o espaço é uno e múltiplo (SUERTAGARAY, 2001), pois há unidade na diversidade e diversidade na unidade complexa (MORIN, 2015). 
Por fim, consideremos o turismo como um fenômeno social complexo, que opera em um ecossistema (BENI; MOESCH, 2017). Ainda, o tenhamos como parte importante na maneira pela qual percebemos e sentimos o mundo, onde quer que estejamos, o que quer que façamos. O fenômeno porta seu próprio kit de técnicas, tecnologias, predisposições e sensibilidades estéticas (FRANKLIN; CRANG, 2001).

\section{Paisagens lacustres e práticas turísticas/de lazer}

A grande abrangência do conceito e do estudo da paisagem exige sua aplicação em muitas áreas, e não causa surpresa que atinja o campo do Turismo (TERKENLI, 2007). As tendências no estudo das paisagens turísticas dividem-se em: construção físico-material dos sítios turísticos; representações do turismo; e, experiência das paisagens (KNUDSEN; METRO-ROLAND; RICKLY-BOYD, 2013). A paisagem figura como categoria a ser contemplada no diagnóstico e planejamento do turismo, ao proporcionar amplas possibilidades de análise do grau de preservação ambiental e orientar a avaliação dos recursos para o aproveitamento turístico (PIRES, 2011). Notamos a variabilidade nas aproximações possíveis ao conceito geográfico de paisagem, o que se reflete nas múltiplas possibilidades ou pontos de acesso do estudo da paisagem no/do/pelo Turismo.

Ao visitarem um destino, os turistas não olham para objetos individuais, mas para uma paisagem turística na sua inteireza, a qual é eminentemente cultural (KNUDSEN; RICKLYBOYD; METRO-ROLAND, 2013). Embora a paisagem não sejam um elemento que por si explique a atratividade turística das localidades, é um fator que pesa muito, em termos de estranhamento e familiaridades (CRUZ, 2002; YÁZIGI, 2002). Não há atratividade a priori no turismo, mas sim um processo semiótico de atribuição de significados, a partir de atrativos e seus marcadores (MACCANNNELL, 1999). Assim, uma paisagem avaliada socialmente de modo positivo pode ou não ser uma paisagem com grande potencial estético (BROOK, 2014). As paisagens turísticas são resultantes da valorização diferencial, pela prática sócio-espacial do Turismo, de alguns arranjos e formas, quer naturais, quer antrópicas, num determinado espaço-tempo. Elas podem reforçar e dar origens a determinados arquétipos das paisagens e lugares, como o das praias tropicais (CRUZ, 2002; YÁZIGI, 2002). No turismo, não há somente a paisagem a ser contemplada, mas também paisagens ordenadas previamente com fins de contemplação (CASTROGIOVANNI, 2001). O deslocamento turístico pressupõe, entre outros aspectos, olhar para aquilo que já foi visto, ou homologar aquilo em que se 
acredita, a partir de prescrições sobre o que ver, sob que condições e como valorar o que foi visto (MENESES, 2002; GOMES, 2013).

Paisagens e mapas, fortemente pictóricos, conectam decisivamente a Geografia ao sentido da visão, que embora não seja o único relevante, ainda possui força no saber-fazer geográfico (COSGROVE, 2008). A imagem territorial está intimamente relacionada ao que entendemos por paisagem (CORRÊA, 2011). Imagens visuais determinam certos mitos dos lugares, contendo estereótipos e clichês (CRAWSHAW; URRY, 1999).

Se o sentido da visão, e o imagético, são relevantes para entendermos a contemplação das paisagens, então o olhar turístico (tourist gaze) também o é. Esse conceito ressalta que olhar é uma habilidade que pode ser aprendida. Ver é o que o olho humano faz; já o gazing se refere a determinações discursivas do olhar socialmente construído. $\mathrm{O}$ olhar turístico compreende discursos, práticas visuais aprendidas, signos, tecnologias visuais, sightseeing, uso de câmeras, e em alguns casos, o visualmente extraordinário (LARSEN; URRY, 2011). O olhar turístico romântico requer contemplação solitária, diferentemente do olhar turístico coletivo, que ocorre em meio a multidões (URRY, 1996). Num sítio turístico, há reflexividade dos olhares de observador e observado, entre a comunidade e os turistas, e entre os turistas (MINCA, 2007). A visibilidade é também composta por uma ou mais práticas (GOMES, 2013). As paisagens também são performadas! (CRESSWELL, 2002) A própria fotografia turística pode ser considerada uma performance (CRANG, 1999), a qual é prescrita, não importando a tipologia do sítio ou paisagem visitada pelos turistas.

Desse modo, procuramos lançar luz sobre os modos pelos quais a paisagem forma as experiências turísticas, não apenas pelo olhar, mas levando em consideração a materialidade e os múltiplos sentidos (TERKENLI, 2007). As experiências do turismo, especialmente a das paisagens, ocorrem como um caleidoscópio de impressões multissensoriais, e não meramente uma perspectiva e um horizonte (CROUCH; ARONSSON; WAHLSTRÖM, 2001). A visão ocorre em encontros que são multissensoriais, ela não ocorre sozinha (CROUCH; LÜBBREN, 2002). Historicamente, a emergência de certas práticas turísticas (como o alpinismo) está alicerçada em mudanças na percepção estética da paisagem (como as montanhas), em que o sublime e o pitoresco, como categorias do Romântico, ainda exercem notória influência, apesar de as performances terem-se diversificado desde então (GASTAL, 2013; TUAN, 2012). As práticas são consideradas atos corporificados de paisagem, mudando a ênfase da representação e significado, para um conhecimento centrado no corpo (ADEY, 2009). 
Mais do que as instalações ou o ambiente construído, é a performance fator da maior relevância para a existência de um sítio turístico: se a performance da mobilidade turística deixa de ocorrer, se o movimento cessa, os sítios turísticos cessam de sê-lo como tais (SHELLER; URRY, 2004), ou seja, a performance os ativa turisticamente. As práticas e performances, embora tenham trajetórias teórico-conceitual distinguíveis, por vezes se aproximam. Ambas podem ser realizadas pelo outro, ou pelo próprio self, como uma mostra de identidades em constituição. As performances nem sempre são conscientes, ou dirigidas a um fim específico; ou seja, nem sempre há intencionalidade clara por parte do sujeito. E, em vez de solitárias, as práticas turísticas são intersubjetivas. As paisagens turísticas são corporificadas, e ganham significado socialmente e corporeamente, por meio da relação com a alteridade (CROUCH; ARONSSON; WAHLSTRÖM, 2001).

Quais as principais práticas/performances prescritas para cada sítio de encontro, e para a Lagoa como um todo? O que cada sítio de encontro tem a aportar, em termos de significações (inter)textuais das paisagens lacustres em questão? É possível observar a dialógica e a recursividade entre representações imagéticas paisagísticas e as práticas/performances turísticas, às margens das lagoas como Mirim, ou não?

\section{Sítios de encontro como partes de um todo (Lagoa Mirim)}

Primeiro, é necessário termos a noção do todo, para estudar as suas partes; por fim, retornando e recompondo o todo do objeto empírico de conhecimento. A Mirim está localizada em uma enorme planície costeira na área mais meridional do Brasil, e a nordeste do Uruguai, e é separada do Oceano Atlântico por uma extensa e estreita faixa de terrenos baixos, unindo-se à Laguna dos Patos pelo exutório do Canal de São Gonçalo, na altura de Pelotas e Rio Grande, e neste município, ao Oceano Atlântico (ASCHKAR; DOMINGUEZ; PESCE, 2012; BASSO, 2012; SCHÄFER et al., 2009).

O talvegue da Lagoa serve como limite entre o Brasil e o Uruguai em determinadas porções. A superfície da bacia hidrográfica - unidade de gestão da política hídrica brasileira da Mirim está em torno de 50\% em cada "lado" desse limite internacional. Embora a superfície das águas da Lagoa correspondam 2/3 ao Brasil e 1/3 ao Uruguai, prevalece o regime de águas compartilhadas, de acordo com tratados assinados nos anos 1970 - Tratado de Cooperação para o Aproveitamento dos Recursos Naturais e o Desenvolvimento da Bacia da Lagoa Mirim (1977) e o Protocolo para o Aproveitamento dos Recursos Hídricos do Trecho Limítrofe do Rio Jaguarão - 1978 (ALBA, 2010; ALM, 2019). 
Mirim vem do tupi mi'ri, e significa pequena. A Lagoa, mesmo com o nome remetendo à pequenez ou à infância - é o segundo maior lago do Brasil (a maior das lagoas), atrás apenas da Laguna dos Patos; e é a maior do Uruguai. Quando comparada à Laguna dos Patos, é que a Lagoa Mirim recebe esse nome. A Lagoa Mirim ocupa uma superfície de $3.749 \mathrm{~km}^{2}$, possuindo $185 \mathrm{~km}$ de extensão e largura de $20 \mathrm{~km}$, em média. A profundidade é de 6m em média (ALBA, 2010; ASCHKAR; DOMINGUEZ; PESCE, 2012; BASSO, 2012; ALM, 2019).

A Figura 1 apresenta mapa de localização da Lagoa Mirim e dos três sítios de estudo - a serem explicitados na seção 3.
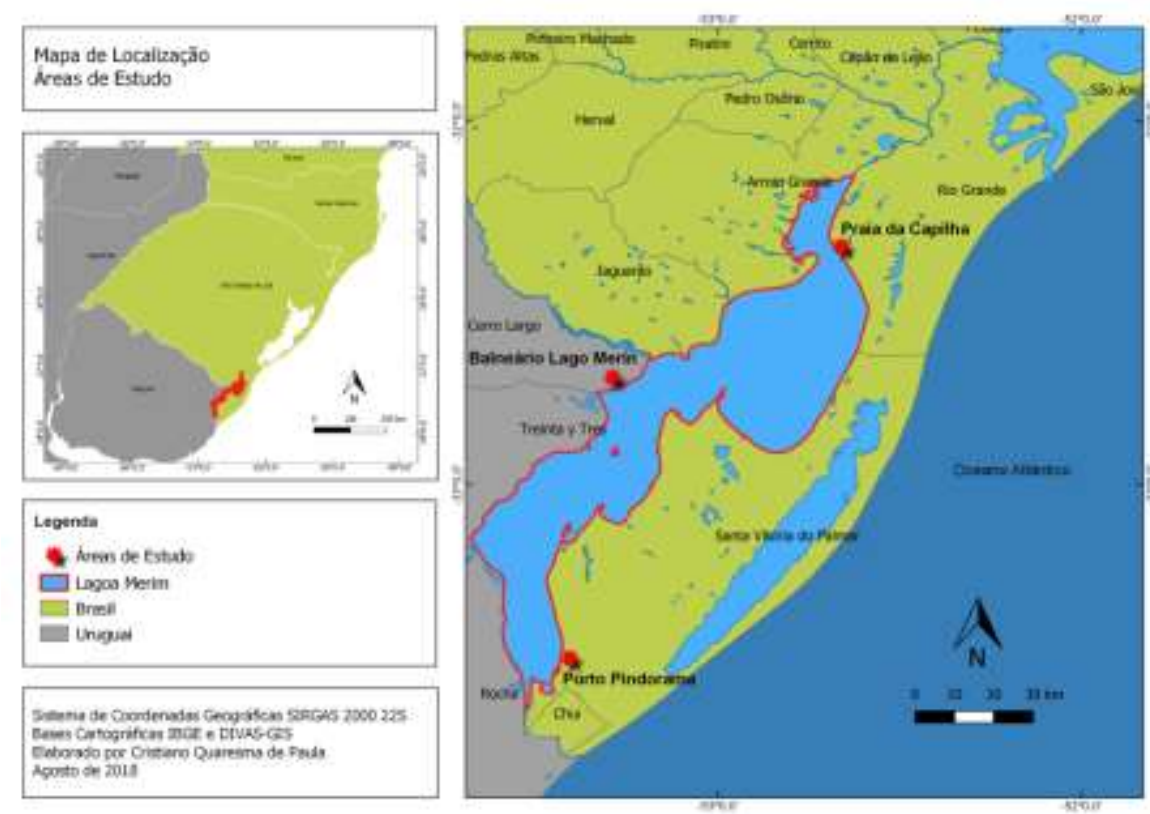

Figura 1 - Localização da Lagoa Mirim e dos sítios de estudo

Fonte: Elaboração de Cristiano Quaresma de Paula (2018).

Conforme se pode visualizar no mapa da Figura 1, o município que possui a margem é mais extensa é Santa Vitória do Palmar - desde as proximidades do Fortín de São Miguel ${ }^{3}$, próximo ao Chuí, até o limite com o município de Rio Grande, na altura da Estação Ecológica do Taim - ESEC Taim. A peculiaridade da Bacia Hidrográfica da Lagoa, que é binacional, representa um singular desafio à gestão de suas águas, envolvendo um cenário complexo e instituições e atores, contudo interligados por um interesse comum (MACHADO, 2012).

Em termos geológicos, a gênese das paisagens às margens da Lagoa Mirim devem suas características à formação da Planície Costeira do RS - PCRS (no Brasil), que expõe a porção superficial de uma enorme sequência de sedimentos, depositados em ambientes

\footnotetext{
${ }^{3}$ Foi construído pelos Portugueses em 1737 e tomado pelos espanhóis três anos mais tarde.
} 
marinhos, continentais e de transição. Isso é resultante de processos da tectônica global e da dinâmica costeira. Trata-se de uma acumulação hídrica em depressão tectônica (VILWOCK; TOMAZELLI, 2007; ACHKAR; DOMINGUEZ; PESCE, 2012). Eventos de regressão/transgressão marinhas dos últimos seis mil anos, ocorridas a partir do período geológico Quaternário (cerca de 400.000 anos atrás) foram decisivas para a configuração da paisagem da PCRS e formação de suas lagoas, uma de suas feições características, formando um dos maiores complexos lagunares do mundo (Laguna dos Patos, Lagoas Mirim e Mangueira), um ecossistema considerado único no mundo (VILWOCK; TOMAZELLI, 2007; SCHÄFER, 2009; ALBA, 2010).

As águas da Lagoa Mirim e da Lagoa Mangueira sustentam as atividades econômicachave na região, quais sejam, pesca, pecuária (bovinos e ovinos) e, especialmente, rizicultura. Esta cultura utiliza as Terras Baixas, a partir de um sistema de irrigação por gravidade ou inundação, o menos eficiente, fazendo intensificar os conflitos advindos desse modelo de "venda da água" (BASSO, 2012). As lavouras de arroz, além do impacto ambiental da contaminação por agrotóxicos (águas superficiais e subterrâneas), têm repercussões ecossistêmicas ainda negativas com a construção de diques de drenagem. As áreas foram tidas como improdutivas, e a fim de ampliar a fronteira agrícola arrozeira, era necessário dessecálas. (ACHKAR; DOMINGUEZ; PESCE, 2012).

Apesar dos impactos das atividades realizadas, a economia é considerada pouco dinâmica, situação usual em fronteiras sul-americanas. A densidade populacional é baixa em ambas as margens, brasileiras e uruguaias. Diante desse quadro, que inclui excedentes de mão-de-obra pelo uso de mecanização, pela precarização do trabalho e pela desterritorialização de campesinos, a população e os governos procuram alternativas de renda e emprego para melhorar a qualidade de vida das populações, inclusive com novos cultivos no meio rural (ALBA, 2010; ACHKAR; DOMINGUEZ; PESCE, 2012; ALM, 2019).

O uso do território nesta porção do Brasil e do Uruguai remonta à formação sócioespacial da área, ligada especialmente aos processos de ocupação e povoamento ocorridos a partir da colonização, e os conflitos e concertações inerentes à consolidação de limites internacionais. A porção extremo sul do Brasil foi contestada entre Portugal e Espanha durante muito tempo, até ser considerada Campos Neutrais, e nesse contexto, a Lagoa foi importante alvo e motivo de defesa e vigilância. Foi designada como zona neutra em 1777 (Campos Neutrais), entre os Arroios Chuí e Taim. Era então chamada de Península do Albardão essa porção entre a Lagoa Mirim e o Oceano (EMYGDIO, 2008). Em 1909 é 
celebrado o Tratado que dispõe sobre a fixação dos limites internacionais entre Brasil e Uruguai, tal como se conhece atualmente.

No primeiro quarto do século passado, a navegação lacustre de cargas era intensa, cujas rotas principais eram entre Santa Vitória do Palmar, Jaguarão, Rio Grande e Porto Alegre, inclusive com registros de diversos naufrágios a essa época. Entretanto, com o fim da navegação comercial, nos anos 1960, a Lagoa caiu em relativo esquecimento. Nos anos 1970, a BR-471 acabou se tornando o principal meio de acesso à região. (EMYGDIO, 2008; ALBA, 2010). Tal situação de inativação não se alterou nos anos mais recentes, em que pesem políticas e projetos para implantação de infraestruturas necessárias a um transporte multimodal (ferroviário e hidroviário) no sistema Mirim-Patos e rios uruguaios tributários.

$\mathrm{Na}$ parte do território compreendida entre a Lagoa e o mar, está um dos mais importantes corredores turísticos que ligam o sul do Brasil e o balneário de Punta del Este, no Uruguai. Entretanto, as principais razões para os turistas virem à região transfronteiriça estão ligadas a compras em free shops ${ }^{4}$ e ao veraneio em praias oceânicas de Santa Vitória do Palmar e praias do Departamento de Rocha, no Uruguai. No "lado" brasileiro, sobretudo, turistas e sujeitos do local parecem preferir a água salgada do mar, geralmente bravio. Contudo, tal situação pode estar se alterando, com a crescente procura pela Vila da Capilha.

A Praia da Vila da Capilha (capilla significa capela, em espanhol), fundada em 1832, fica no município de Rio Grande-RS, Brasil, ponto onde a costa da lagoa está mais próxima da rodovia BR-471. A localidade é destino em ascensão para os viajantes de um dia, e turistas de temporada, está a cerca de $1 \mathrm{~h}$ em automóvel da cidade de Pelotas, centro regional, juntamente com a portuária Rio Grande. Da capela é possível descender à praia por uma passarela. A Figura 1 apresenta uma foto do centro da Vila da Capilha.

\footnotetext{
${ }^{4}$ Existem atualmente no Uruguai, e atualmente existem projetos para instalação também no "lado" brasileiro.
} 


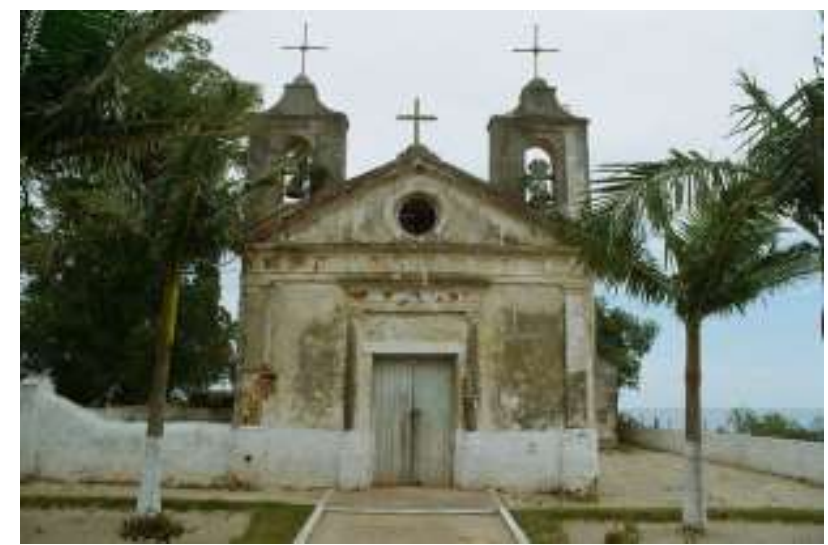

Figura 1 - Vila da Capilha (capela e Lagoa)

Fonte: G. Pinheiro (2018), disponível no Flickr.

A Praia da Capilha está na maior enseada da Mirim, com 53 milhas de praia, é também a parte mais larga da lagoa. A capela, chamada de Nossa Senhora da Conceição do Tahym, está à beira da barranca - falésia (EMYGDIO, 2008). O conjunto formado pela Estação Ecológica do Taim e o formado pela Vila do Taim e a margem da Lagoa Mirim mais conhecida como Vila da Capilha, em Rio Grande - são consideradas belezas cênicas do pampa gaúcho (VIEIRA, 2014). A Praia/Vila da Capilha e o entorno da ESEC do Taim são consideradas de interesse ecológico, estético e recreativo (RUDZEWICZ, 2018).

Houve a inclusão da Vila da Capilha na Zona de Amortecimento de Impactos ${ }^{5}$ na ESEC Taim, que se encontra em expansão (ICMBio, 2013). O turismo ecológico é visto pelos especialistas como atividade pouco impactante, compatível com as ZAs. Trilhas ecológicas são oferecidas no entorno da ESEC, como atividades desenvolvidas pelas comunidades locais. Em conjunto a ONGs e à ESEC Taim, divulgam-se modos de vida tradicionais, aspectos históricos e as belezas cênicas da ESEC (SCHREINER, 2012).

A inclusão da Capilha como ZA da ESEC pode ter, como vantagens: o fortalecimento da relação da ESEC com a comunidade residente na vila, pela co-gestão; organização da oferta de atividades do turismo; conservação patrimonial e ambiental; e, obtenção de apoio político. Porém, a inserção da Vila na ZA da Esec pode impedir o desenvolvimento da localidade, dadas as restrições por ela previstas, uma vez a Vila não pode ser transformada em área densamente urbanizado. Além disso, pode trazer uma série de procedimentos burocráticos de licenciamento ambiental, já que as atividades dentro da ZA necessitariam passar pelo crivo da ESEC (SCHREINER, 2012).

\footnotetext{
${ }^{5}$ Havia um grupo de trabalho estudando a ampliação da área da ESEC, a partir de diferentes critérios de inclusão e exclusão. Por exemplo, incluir áreas contíguas ao canal que liga o Banhado do Taim à Lagoa Mirim. Aprovou-se a proposta de ampliação (PUCCINELLI, 2016).
} 
Embora a Capilha não seja mencionada, pela Secretaria de Estado da Cultura, Turismo, Esporte e Lazer, como atrativo do município de Rio Grande (TURISMO RS, 2019), no site da Prefeitura de Rio Grande, a Capilha é considerada atrativo natural. É descrita a partir de aspectos culturais (a capela) e naturais (lagoa, e entorno do Taim). Aparecem prescrições/orientações quanto às práticas passíveis de serem realizadas. Na íntegra:

Esta comunidade localizada na BR 471 a $60 \mathrm{~km}$ do centro de Rio Grande, possui a Capela de Nossa Senhora da Conceição, que é uma das mais antigas construções da fronteira sul do Brasil, sendo a primeira edificação construída em 1785. Contempla a praia banhada pelas águas da Lagoa Mirim de uma beleza exuberante, onde os visitantes podem transitar de carro, acampar, praticar esportes, desfrutar da gastronomia local através de dois restaurantes e uma praia tranquila bem perto da Reserva Ecológica do Taim. (RIO GRANDE, 2019, s. p.).

Além das áreas historicamente consagradas ao turismo em Rio Grande, como as áreas central e a do Balneário Cassino, a Lagoa Mirim é recentemente apontada como um dos novos territórios do turismo nesse município. Órgãos oficiais manifestam tanto interesse pela diversificação da oferta turística municipal, quanto preocupação com o aumento de visitantes na Capilha (RUDZEWICZ, 2018).

O Porto Pindorama, em Santa Vitória do Palmar-RS, Brasil, é o porto mais meridional do Brasil, embora desativado. O terminal assume o formato de barco. É possível observar, a sudoeste, o "lado" uruguaio - parte da fronteira observável é o Cerro San Miguel, onde está o forte homônimo. O Porto também é considerado beleza cênica pontual (VIEIRA, 2014). A descrição do município, pela Prefeitura Municipal, na guia "turismo", do mesmo site, há as seções gastronomia (citam-se o butiá, a carne de ovelha e os pescados), Rota dos Faróis - a cidade conta com três faróis, um deles na divisa com Rio Grande ${ }^{6}$ - balneários (Hermenegildo ${ }^{7}$ e Barra do Chuí) e o Porto - ou seja, este não é visto como propriamente um balneário, supostamente por não ser marítimo e/ou por não ter tido urbanização turística específica para lazer e recreação, ou segundas residências (SANTA VITÓRIA DO PALMAR, 2019). Ainda percorrendo o mesmo site, o Porto, na continguidade com o centro urbano, é apresentado como obra de engenharia, revitalizado, e como promessa de emprego e renda pelo turismo. Há orientações/prescrições sobre o que praticar ali em termos de lazer, bem como o modo apreciar a paisagem: o pôr do sol é recomendado. Na íntegra:

\footnotetext{
${ }^{6}$ Dois deles construídos em 1942, os outros dois, em 1964 (SANTA VITÓRIA DO PALMAR, 2019).

${ }^{7}$ O site coloca a praia do Hermenegildo como se estendendo por $119 \mathrm{~km}$, até a divisa com Rio Grande (SANTA VITÓRIA DO PALMAR, 2019).
} 
Com uma vista inigualável da Lagoa Mirim, a cerca de 10 minutos do centro da cidade, Santa Vitória do Palmar abriga um pequeno porto lacustre às margens da lagoa. A obra, iniciada em 1942, foi considerada a maior de engenharia até os anos 50 e, nos últimos anos, recursos têm sido investidos na sua revitalização. Além de atender o modal hidroviário da região, como uma porta de entrada e saída de comércio do Mercosul, o Porto atua também como chamariz turístico, de forma a aproveitar o potencial natural para a geração de emprego e renda de maneira sustentável.

Suas instalações consistem em um píer com extensão total de 451,10 metros, fazendo do Porto um lugar perfeito para tomar um chimarrão com os amigos à tardinha ou aproveitar para relaxar lendo um bom livro. O local atrai também os apaixonados pelo desporto e é indicado para a prática de esportes aquáticos como stand up paddle, caiaquismo e pesca. O Porto santa-vitoriense é hoje um local para os moradores de Santa Vitória e para os visitantes aproveitarem momentos de lazer e se deslumbrarem com o magnífico pôr-do-sol que a vista do mirante proporciona. (SANTA VITÓRIA DO PALMAR, 2019, s. p.).

Na Figura 2, está a foto está o trapiche, em que aparecem bancos e iluminação (no primeiro plano), com águas da lagoa ladeando, e ao fundo centralizado o prédio do porto.

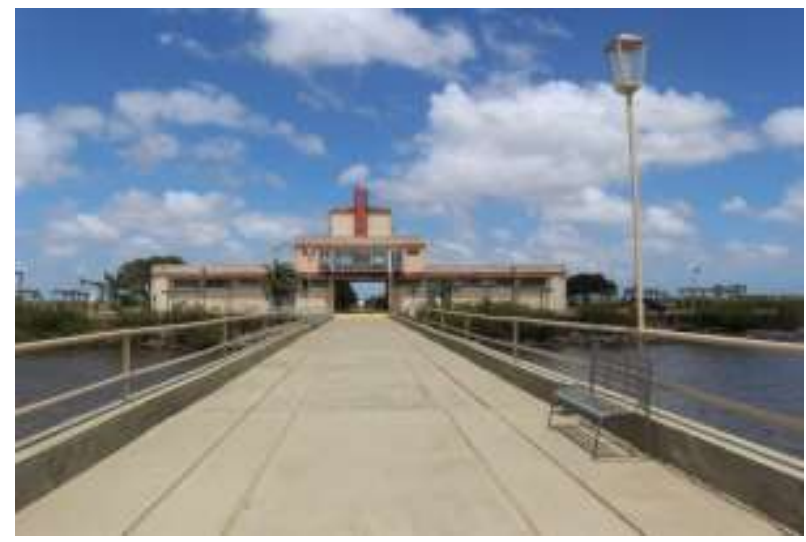

Figura 2 - Porto de Santa Vitória em divulgação da Prefeitura

Fonte: Prefeitura de Santa Vitória do Palmar (2019) - não há como precisar a data da foto.

O estudo de Silva (2014) demonstrou que o Porto é um lugar apropriado por seus frequentadores como local de sociabilidade, memória e afetividade. Dada a proximidade e o espaço convidativo, os sujeitos são cidadãos-turistas, oriundos da própria cidade. Já Mello (2017), contextualizando a reconversão de estruturas portuárias para o turismo e lazer urbanos, discutiu as repercussões do projeto de revitalização do Porto e seu entorno, entre 2006 e 2008, o qual contou aportes financeiros do Ministério do Turismo. Houve restauro do terminal, combinado à revalorização do entorno - por exemplo, mobiliário urbano. Contudo, passada uma década da inauguração, considera-se que as estratégias de planejamento para ativação turística do local foram insuficientes. E, embora haja o discurso de potencial turístico por parte da comunidade local, o Porto é reconhecido pela infraestrutura insuficiente, 
sobretudo das condições do segmento final da estrada de acesso, bem como pela falta de animação turístico-cultural.

Também, o enquadramento do Porto em IP4, o fato de ser área de Marinha, bem como a falta de um Plano Diretor para o Porto (ordenamento), seriam empecilhos para o estabelecimento de empreendimentos turístico-recreativos. O local não conta com a presença da Marinha, Capitania dos Portos ou alfândega. O Porto foi usado como símbolo da cidade pela Administração municipal anterior. Parece carecer da inserção da comunidade, bem como de interpretação patrimonial (MELLO, 2017).

Por fim, falamos sobre Lago Merín, no departamento de Cerro Largo, Uruguai. É um balneário lacustre planejado para lazer, talvez um dos únicos ao longo da Lagoa Mirim. $\mathrm{O}$ Balneário de Laguna Merín (homônimo da Lagoa) data de década de 1930, fundado para ser uma colônia para tratamento de tuberculose, dados os ventos favoráveis. Estando no "lado" uruguaio, fica a $30 \mathrm{~km}$ de Jaguarão, município brasileiro que serve como portão de entrada e que conta com conjunto de patrimônio histórico tombado. O núcleo urbano conformado pelas cidades-gêmeas de Jaguarão e Rio Branco são também destinos de compras, para brasileiros e uruguaios, possuindo, além de free shops, um cassino (lado uruguaio). O público do Balneário durante a temporada é formado, principalmente, por uruguaios, mas também por brasileiros. Muitos possuem segunda residência.

Na década de 1930 iniciou o loteamento e venda de terrenos do Balneário Lago Merín, local então habitado por pescadores artesanais e caçadores. A partir da promoção do Balneário como destino turístico, começam a chegar à área sujeitos com distintos perfil turísticos, muitos dos quais aposentados oriundos de Melo e Treinta y Tres (MIGLIARO, 2014). Foi declaro sítio de interesse turístico nacional nos anos 1940.

A Figura 3 mostra fotografia de paisagem do Balneário.

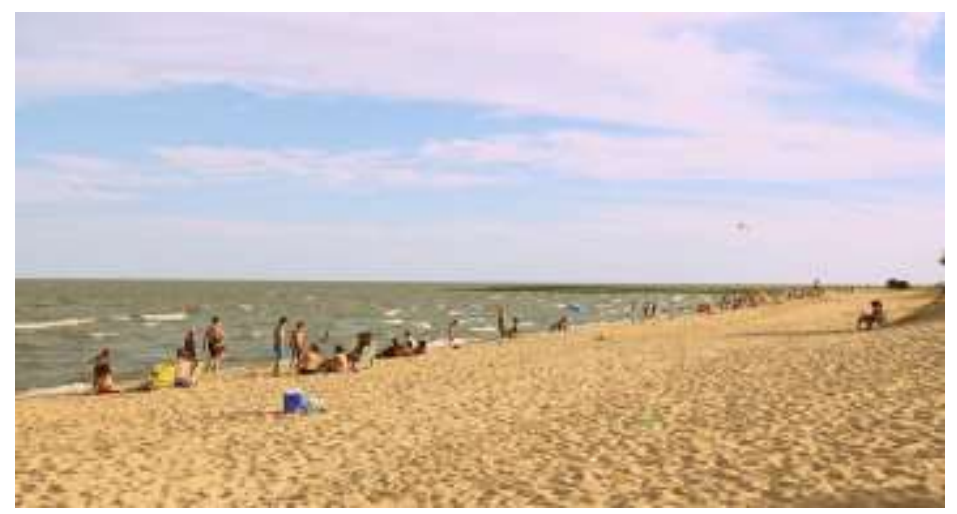

Figura 3 - Paisagem de Lago Merín na temporada de verão

Fonte: G. Felito (2013), disponível no Flickr. 
A maioria da população economicamente ativa da localidade combina atividades características do turismo e atividades agropecuárias ou à pesca artesanal. Há alguns hotéis, pousadas e cabanas para aluguel. Casas de comércio mantém-se abertos durante a temporada, sendo escassos os serviços permanentes. É relativamente recente o começo de atividades de um turismo de natureza. Encontram-se nas margens do Taquari, naquela região, algumas estâncias turísticas dedicadas à caça esportiva (MIGLIARO, 2014).

Há dois tipos de turismo claramente identificáveis na área. O primeiro, ligado ao Balneário de Lago Merín, com utilização da praia, realização de esportes náuticos e a presença de alguma infraestrutura, inclusive de alojamento hoteleiro. Este tipo não afeta as atividades dos pescadores, podendo contribuir com complementação de renda. O outro tipo de turismo é de caráter privativo, alijado do balneário, assentando-se em sítios privados. Mesmo com a proposta de um ecoturismo, acabam levantando suspeita quanto a um impacto ambiental pela mortandade de animais. $\mathrm{O}$ acesso é por estradas privadas, ocorrendo pouco contato com a população local (MIGLIARO, 2014).

$\mathrm{Na}$ indisponibilidade de um site oficial do turismo de Lago Merín/Río Branco, analisamos o conteúdo de dois vídeos no YouTube, do canal Uruguay Natural, do Ministério do Turismo do países. Nesses dois vídeos (https://www.youtube.com/ watch?v=kOxfUOlaFxQ; https://www.youtube.com/watch?v=x1 QpgObGDKQ\&t=5s), além da menção de paisagens lacustres atraentes, são apontadas como práticas, no texto verbalizado, a reflexão, o pôr do sol, e atividades esportivas, culturais e noturnas (não especificadas).

A Quadro 1 apresenta o comparativo e a síntese de práticas e performances preconizadas para cada sítio de encontro estudado.

Quadro 1 - Práticas e performances prescritas para cada sítio

\begin{tabular}{|c|c|}
\hline Sítio de encontro & Práticas/performances previstas \\
\hline $\begin{array}{c}\text { Praia da Vila da Capilha, Rio Grande- } \\
\text { RS, Brasil }\end{array}$ & $\begin{array}{c}\text { - Transitar de carro } \\
\text { - Acampar } \\
\text { - Praticar desportos (não especificados) } \\
\text { - Desfrutar da gastronomia local } \\
\end{array}$ \\
\hline $\begin{array}{c}\text { Porto Pindorama, Santa Vitória do } \\
\text { Palmar-RS, Brasil }\end{array}$ & $\begin{array}{c}\text { - Tomar chimarrão (com amigos, à tardinha) } \\
\text { - Relaxar lendo um bom livro } \\
\text { - Realizar desportos (stand up paddle, caiaquismo,...) } \\
\text { - Pescar }\end{array}$ \\
\hline $\begin{array}{l}\text { Balneário de Lago Merín, Río Branco- } \\
\text { Cerro Largo, Uruguai }\end{array}$ & $\begin{array}{c}\text { - Refletir } \\
\text { - Admirar o pôr do sol } \\
\text { - Realizar desportos, atividades culturais e noturnas (não } \\
\text { especificadas) }\end{array}$ \\
\hline
\end{tabular}

Fonte: Sites das Prefeituras Municipais - cidades brasileiras (2019), e do canal Uruguay Natural no YouTube

Departamento de Cerro Largo - Uruguai (2013, 2016) 
Quando se fala em tomar chimarrão, está-se falando de uma prática, orientada por identidade. Quando se está sugerindo fazê-lo à tardinha (quando ocorre o pôr do sol), e na companhia de amigos, está-se falando de uma performance delimitada, codificada, representacional e socialmente compartilhada e replicada. Código, representação e réplica são conceitos semióticos, que aqui são complexificados mediante a abordagem de paisagens e práticas. A mídia e as práticas formam um círculo representacional que se retroalimenta. Se os turistas não encontrar orientações sobre o que é melhor de se fazer em cada sítio (além do que observar), poderão sentir-se desorientados. Por outro lado, as recomendações a esse respeito, divulgadas em veículos oficiais, midiáticos, e também pela mídia social (turista a turista) correspondem à aquilo que o sujeito-turista busca realizar, como uma performance praticamente teatral, que conta com roteiro, cenário, e até mesmo figurinos, relativamente demarcados.

Por um lado, cada sítio apresenta suas próprias práticas como expressões e agendamentos turísticos, assim, cada qual pode se complementar (como partes). Por outro, a falta de uma diretriz enquanto à imagem, à representação e às práticas pode deixar, como se disse, os turistas de certos modo incertos quanto ao que buscarem na Lagoa, ou como agirem. Com relação à trajetória de cada sítio, concordamos com MacCannell (2001) quando diz que somente alguns dos alvos do olhar do turista foram de fato feitos para funcionar em prioritariamente como atrações - Lago Merín. A maioria das delas foi feita para servir a outras finalidades, ou a finalidade nenhuma, como no caso dos atrativos naturais - a Lagoa como um todo, objeto que pré-existe a toda intencionalidade turística e/ou de lazer e a toda semiose. Constitui-se originalmente como ecossistema e como feição marcante da paisagem da Planície Costeira brasileiro-uruguaia. É o processo de interpretação da paisagem-signo que a torna visível pelo/para o turismo.

Lago Merín, e em menor medida, a Capilha, são manifestações particulares das vacationscapes - paisagens de férias (LÖFGREN, 1999), que emergem da/na história social do turismo. São, de modo mais pronuncionado, sítios do hedonismo, em que podem ocorrer eventos, aventuras e/ou férias em família. E, mesmo após o veraneio e/ou durante o inverno, o Balneário prossegue como índice, ou sinal, da cultura material remanescente de uma vida de férias/feriado. A paisagem não está abandonada, mas repleta de sonhos e imaginários para a próxima temporada! (LÖFGREN, 1999).

Quando pensamos no todo da Lagoa Mirim, consideremos sua grande extensão. Do mesmo modo, comparemos o território do Brasil e do Uruguai, este bem mais extenso que o 
daquele. Isso depõe sobre o que a mesma Lagoa, em distintas secções/partes, representa em termos de projeção turística para os respectivos países de seus domínios. Estamos falando de uma questão de escala. A escala dimensional diz respeito ao tamanho das formas simbólicas ou econômicas, diferente da cartográfica que é a do mapa, que representa processos e formas por meio de relações numéricas. Lembremos que uma teoria elaborada em uma dada escala não pode ser transferida para outra (CORRÊA, 2018). Ou seja, o que é verdadeiro para a Lagoa Mirim (todo), pode não ser válido para cada uma de suas secções, se situadas no Brasil, ou no Uruguai, o que pode vir a conformar uma problemática típica das fronteiras.

Também falemos dos arranjos socioespaciais. Como uma forma da espacialidade, o arranjo representa uma pausa, pequena ou grande, no movimento da sociedade. A pausa e a forma é que dão uma morfologia ao espaço. Arranjos revelam padrões espaciais, que podem ser simples ou complexos, dentro das possibilidades de uma sociedade, em dada época. Pode haver refuncionalização do arranjo, possuindo este uma escala, de dispersão ou concentração. (CORRÊA, 2018). São exemplos de arranjos a vila da Capilha, o comunidade do Porto e o Balneário de Lago Merín, este último originalmente funcionalizado pelo/para o turismo/lazer; e aqueles, comunidades pesqueiras que recebem afluxo de visitantes, de escala pequena, e relativa concentração. Se o critério for superfície do uso de solo para fins de urbanização turística, a região onde está a Lagoa Mirim não parece ser tipicamente turística. Mas, uma vez tomados como pontos de ativação turística - o que é realizado não só mediante o olhar às paisagens, mas às práticas e performances corporificados - vêem-se os sítios de encontro como lócus da prática sazonal, pontual, diferenciada, combinada e seletiva das mobilidades turísticas e de lazer, que se imbricam.

\section{Considerações finais}

Quanto às limitações do trabalho, ressaltamos o desafio da pesquisa em espaços transfronteiriços, com bases de dados e denominações distintos, recortes territoriais, para fim de gestão hídrica e turística, que se sobrepõem. Ainda, a tarefa por vezes árdua de articular o léxico da ciência geográfica, com o saber-fazer do turismo, que muitas vezes opta por terminologia própria em seu planejamento/gestão turísticos.

Notemos que cada um desses sítios tem forjada, a sua maneira, e de acordo com a diferenciação dos processos sócio-espaciais, a natureza do encontro turístico/de lazer dos sujeitos com as paisagens lacustres do corpo d'água "Mirim". Vê-se como o Turismo/Lazer dialogam, por meio da estética da paisagem, com o ambiente natural e também com 
rugosidades do ambiente construído, nos três sítios. O(s) objeto(s) estudado(s) fazem parte da semiose por parte de turistas, gestores e comunidades residentes, em uma intertextualidade dos marcadores turísticos (MACCANNELL, 1999), compartindo significados por vezes dissonantes ou complementares.

Marcadores dissonantes podem apontam para a necessária diferenciação e complementaridade espaciais que constam das rotas, roteiros e/ou circuitos turísticos. Por outro lado, podem dificultar a consolidação de uma imaginário turístico e um posicionamento de mercado claros e eficazes juntos aos sujeitos, que, quer queira, quer não, realizam uma forma de consumo, o que não se limita, a uma relação de compra. O consumo de signos e símbolos é um dos principais componentes das experiências turísticas, já no pré-viagem, estendendo-se até a rememoração no pós-viagem, e o compartilhamento de experiências com outros sujeitos.

Acreditamos que um dos desdobramentos teórico-práticos deste projeto, uma vez finalizado e apresentado, vá apontar para projetos integrados de interpretação da paisagem lacustre, que possam revalorizá-la junto aos sujeitos que já frequentam esses sítios, e com eles e neles desempenham papéis em seus encontros turísticos. Ainda, apontar para diretrizes que façam cada sítio se sobressair, e ao mesmo tempo, somar-se aos demais sítios, ainda que localizados em países distintos, fazendo os turistas circularem pela Lagoa, ainda que as distâncias sejam consideráveis. Notamos, até o momento, que os sujeitos-turistas acessam a Lagoa somente por uma de suas partes, apenas, não tendo um panorama do todo que esse corpo hídrico pode representar.

Dentro dos avanços já obtidos, ainda cabem alguns questionamentos, a serem possivelmente respondidos ao longo da coleta e análise de dados da tese, que se encontra em andamento. Os sítios de encontro da Lagoa Mirim estudados seriam lugares de visibilidade, dentro da relativa invisibilidade turística da Lagoa, como um todo? Quais as principais práticas/performances turísticas desempenhadas pelos sujeitos-turistas como modo de envolvimento mais-que-visual com as paisagens lacustres estudadas? Elas estão em conformidade com o prescrito por órgãos oficiais, ou por outros sujeitos-turistas, conforme disponibilizado em fotografias e blogs? Seriam os sítios da Lagoa Mirim locais em que, na falta de uma normatividade em termos de performance institucionalizada, o turista pode vir a se sentir desorientado quanto ao que praticar, e desse modo, os fazem parecer pouco "turísticos"? 
Agradecimento: Nosso reconhecimento à Capes pela concessão, ao primeiro de autor, de bolsa de doutorado sanduíche no exterior (Estados Unidos) - processo 88881.177703/201801 .

\section{Referências}

ACHKAR, M.; DOMINGUEZ, A.; PESCE, F. Cuenca de la Laguna Merín - Uruguay: aportes para la discusión ciudadana. Redes: Montevideo, 2012. 31 p.

ADEY, P. Mobility. London: Routledge, 2009. 267 p.

ALBA, J. M. F. (Org.). Sustentabilidade socioambiental da Bacia da Lagoa Mirim. Pelotas: Embrapa, 2010. 292 p.

BASSO, L. A. Bacias Hidrográficas do Rio Grande do Sul: implicações ambientais. In: VERDUM, R.; BASSO, L. A.; SUERTEGARAY, D. M. A. (Org.). Rio Grande do Sul: Paisagens e Territórios em transformação. 2. ed. Porto Alegre: Editora da UFRGS, 2012. p. 87-108.

BENI, M. C.; MOESCH, M. M. A teoria da complexidade e o ecossistema de turismo. Turismo: Visão e Ação, v. 19, n. 3, p. 430-457, 2017. ISSN 1983-7151. Disponível em: https://siaiap32. univali.br/seer/index.php/rtva/article/view/11662/6706 Acesso em: $11 \mathrm{dez}$. 2019.

CASTROGIOVAnNI, A. C. Por que geografia no Turismo? Um exemplo de caso: Porto Alegre. In: GASTAL, S. de A. (Org.). Turismo: 9 propostas para um saber-fazer. 2. ed. Porto Alegre: Edipucrs, 2001. p. 131-144.

CORRÊA, R. L. Caminhos paralelos e entrecruzados. São Paulo: Editora Unesp, 2018. 321 p.

2011.

. Denis Cosgrove - a paisagem e as imagens. Espaço e Cultura, v. 1, n. 29, p. 7-21,

COSGROVE, D. Geography and Vision: seeing, imagining and representing the world. London/New York: IB Auris, 2008. 272 p.

Landscape and the European sense of sight - eyeing the nature. In: ANDERSON, K.; DOMOSH, M.; PILE, S.; TRHIFT, N. (Org.). Handbook of Cultural Geography. London: Sage, 2002. p. 249-268.

CRANG, M. Picturing practices: research through the tourist gaze. Progress in Human Geography, v. 21, n. 3, p. 359-373, 1997. ISSN 14780288. Disponível em: https://journals.sagepub.com/doi/10.1191/030913297669603510. Acesso em: 12 dez. 2019. 
CRAWSHAW, C.; URRY, J. Tourism and the photographic eye. In: ROJEK, C.; URRY, J. Touring cultures: transformations of travel and theory. London: Routledge, 1997. p. 176196.

CRESSWELL, T. Landscape and the obliteration of practice. In: ANDERSON, K.; DOMOSH, M.; PILE, S.; TRHIFT, N. (Org.). Handbook of Cultural Geography. London: Sage, 2002. p. 269-282.

CROUCH, D. Flirting with space: thinking landscape relationally. Cultural Geographies, v. 17, n. 1, p. 5-18, 2010. ISSN 14770881. Disponível em: https://doi.org/10.1177/ 1474474009349996. Acesso em: 12 dez. 2019.

Introduction: encounters in leisure/tourism. In: CROUCH, D. (Org.). Leisure/ Tourism Geographies: practices and geographical knowledge. London: Routledge, 1999. p. $1-16$.

CROUCH, D.; ARONSSON, L.; WAHLSTRÖM, L. Tourist encounters. Tourist Studies, v. 1, n. 3, p. 253-270, dez. 2001. ISSN 14687976. Disponível em: https://journals.sagepub. com/doi/10.1177/146879760100100303. Acesso em: 09 dez. 2019.

CROUCH, D.; LÜBBREN, N. Introduction. In: (Org.). Visual culture and tourism. Berg: Oxford/New York, 2003.

CRUZ, R. de C. A. da. As paisagens artificiais criadas pelo turismo. In: YÁZIGI, E. (Org.). Turismo e paisagem. São Paulo: Contexto, 2002. p. 107-119.

EMYGDIO, D. V. Lagoa Mirim: um paraíso ecológico. Pelotas: Ed. UFPel, 2008. 227 p.

FRANKLIN, A.; CRANG, M. The trouble with tourism and travel theory? Tourist Studies, v. 1, n. 1, p. 5-22, 2001. ISSN 17413206. Disponível em: https://doi.org/10.1177/ 146879760100100101. Acesso em: 12 dez. 2019.

GASTAL, S. Imagem, Paisagem e Turismo: a construção do olhar romântico. Pasos, v. 11, n. 3, p. 123-133, 2013. ISSN 16957121. Disponível em: http://www.pasosonline.org/es/ articulos/633-imagem-paisagem-e-turismo-a-construc\%C3\% A3o-do-olhar-romantico.

Acesso em: 12 dez. 2019.

GOMES, P. C. da C. O lugar do olhar: elementos para uma geografia da visibilidade. Rio de Janeiro: Bertrand Brasil, 2013. 320 p.

KNUDSEN, D. C.; METRO-ROLAND, M. M.; RICKLY-BOYD, J. M. Landscape studies and tourism research. In: HOWARD, P.; THOMPSON, I.; WATERTON, E. (Org.). Handbook of Landscape Studies. London: Routledge, 2013. p. 286-295.

LARSEN, J.; URRY, J. Gazing and performing. Environment and Planning D: Society and Space, v. 29, n. 1, p. 1110-1125, 2011. ISSN 14723433.Disponível em: https://doi.org/ 10.1068/d21410. Acesso em: 12 dez. 2019.

LÖFGREN, O. On holiday: a history of vacationing. Berkeley/Los Angeles: University of California Press, 1999. 321 p. 
MACCANNELL, D. The tourist: a new theory of the leisure class. Berkeley/Los Angeles: University of California Press, 1999 [1976]. 231 p.

Tourist Agency. Tourist Studies, v. 1, n. 1, p. 23-37, 2001. ISSN 17413206. Disponível em: https://doi.org/10.1177/146879760100100102. Acesso em: 12 dez. 2019.

MACHADO, J. B. Análise da governança das águas da Bacia Hidrográfica da Lagoa Mirim, extremo sul do Brasil. 2012. 205 f. Dissertação (Mestrado em Gerenciamento Costeiro), Universidade Federal do Rio Grande, Rio Grande, 2012.

MATLESS, D. Introduction. In: ANDERSON, K.; DOMOSH, M.; PILE, S.; TRHIFT, N. (Org.). Handbook of Cultural Geography. London: Sage, 2002. p. 227-232.

MELLO, M. M. Repercussões de um projeto turístico: revitalização do Porto de Santa Vitória do Palmar (2006-2008). 2017. 116f. Trabalho de Conclusão de Curso (Graduação em Turismo), Universidade Federal do Rio Grande, Santa Vitória do Palmar, 2017.

MENESES, U. B. de. A paisagem como fato cultural. In: YÁZIGI, E. (Org.). Turismo e paisagem. São Paulo: Contexto, 2002. p. 29-64.

METRO-ROLAND, M. M. Interpretating meaning: an application of Peircean Semiotics to tourism. Tourism Geographies, v. 11, n. 2, p. 270-279, 2009. ISSN 14701340. Disponível em: https://doi.org/10.1080/14616680902827225. Acesso em: 12 dez. 2019.

MIGLIARO, A. Por la frontera: una mirada psicosocial a los pescadores artesanales en la Cuenca de la Laguna Merín en el Uruguay. 2014. 118f. Dissertação (Mestrado em Psicología Social), Universidad de la República, Montevidéu, 2014.

MINCA, C. The tourist landscape paradox. Social \& Cultural Geography, v. 8, n. 3, p. 433453, jun. 2007. ISSN 14701197. Disponível em: https://doi.org/10.1080/ 14649360701488906. Acesso em: 12 dez. 2019.

MORIN, E. Introdução ao pensamento complexo. 5. ed. Porto Alegre: Sulina, 2015 [2005].

. O Método. 5. ed. Porto Alegre: Sulina, 2011 [1991]. 4v.

PIRES, P. dos S. Marco teórico-metodológico de los estudios del paisaje: perspectivas de aplicación en la planificación del turismo. Estudios y Perspectivas en Turismo, v. 20, n. 3, p. 522-541, 2011. ISSN 03275841. Disponível em: https://www.redalyc.org/pdf/1807/180717583001.pdf. Acesso em: 12 dez. 2019.

Portal da Agência de Desenvolvimento da Bacia da Lagoa Mirim. Disponível em: https://wp.ufpel.edu. br/alm/?page_id=2103. Acesso em: 01 ago. 2019.

Portal da Prefeitura Municipal de Santa Vitória do Palmar. Disponível em: https://santavitoriadopalmar.rs gov.br/municipio/cidade/. Acesso em: 18 jul. 2019.

Portal da Prefeitura Municipal do Rio Grande. Disponível em: http://www.riogrande.rs. gov.br/turista/\#link. Acesso em: 18 jul. 2019. 
Portal da Secretaria da Cultura, Turismo, Esporte e Lazer do Rio Grande do Sul. Disponível em: https://www.turismo.rs.gov.br/regiao/43/regiao-costa-doce. Acesso em: 26 jul. 2019.

Portal do Instituto Chico Mendes de Conservação da Biodiversidade - ICMBio. Disponível em: http://www.icmbio.gov.br/portal/images/stories/o-que-fazemos/consultas_publicas/ RESUMO_EXECUTIVO_Ampliacao_da_ESEC_do_Taim.pdf. Acesso em: 18 dez. 2019.

PUCCINELLI, V. R. Educação ambiental e o participativismo autoritário da preservação: o caso da Estação Ecológica do Taim e a ecologização dos moradores da Vila da Capilha. 2016. 133f. Dissertação (Mestrado em Educação Ambiental), Universidade Federal do Rio Grande, 2016.

ROGER, A. Vida y muerte de los paisajes: valores estéticos, valores ecológicos. In: NOGUÉ, J. (Org.). El paisaje en la cultura contemporánea. Madrid: Biblioteca Nueva, 2008. p. 67-86.

RUDZEWICZ, L. Paisagens lacustres e práticas turísticas: "com os pés na água" ou "de costas para a água?" O caso da Laguna dos Patos, Rio Grande do Sul, Brasil. 2018. 294f. Tese (Doutorado em Geografia) - Universidade Federal do Rio Grande do Sul, Porto Alegre, 2018.

SANTAELLA, L. O que é semiótica? São Paulo: Brasiliense, 2012 [1983]. 80 p.

SANTOS, M. A natureza do espaço: técnica e tempo, razão e emoção. São Paulo: Edusp, 2002. 384 p.

O espaço do cidadão. 4. ed. São Paulo: Nobel, 1998. 142 p.

SCHÄFER, A. E.; LANZER, R.; PEREIRA, R. Atlas socioambiental Lagoas Costeiras I. Caxias do Sul: Educs, 2009. 372 p.

SCHREINER, G. de M. Proposta de cenários para a delimitação de Zona de Amortecimento de Impactos na Estação Ecológica do Taim. 2012. 103f. Dissertação (Mestrado em Gerenciamento Costeiro Integrado), Universidade Federal do Rio Grande, Rio Grande, 2012.

SHELLER, M.; URRY, J. (Org.). Tourism mobilities: places to play, places in play. London: Routledge, 2004. 256 p.

SILVA, A. E. Apropriação do Porto de Santa Vitória do Palmar-RS, por meio do lazer e do turismo cidadão. 2014. 64f. Trabalho de Conclusão de Curso (Graduação em Turismo Binacional), Universidade Federal do Rio Grande, Santa Vitória do Palmar, 2014.

SOUZA, M. L. de. Os conceitos fundamentais da pesquisa sócio-espacial. Rio de Janeiro: Bertrand Brasil, 2013. 320 p.

SUERTEGARAY, D. M. A. Espaço uno e múltiplo. Scripta Nova, n. 93, 2001. ISSN 11389788. Disponível em: http://www.ub.edu/geocrit/sn-93.htm. Acesso em: 12 dez. 2019. 
TERKENLI, T. S. Turismo e paisagem. In: LEW, A. A.; HALL, C. M.; WILLIAMS, A. M. (Org.). Compêndio de Turismo. Lisboa: Instituto Piaget, 2007. p. 381-390.

TUAN, Y.-F. Topofilia: um estudo da percepção, atitudes e valores do meio ambiente. Londrina: Eduel, 2012 [1974]. 342 p.

URRY, J. $O$ olhar do turista: lazer e viagens nas sociedades contemporâneas. São Paulo: Nobel, 1996 [1990]. 231f.

VIEIRA, L. de F. dos S. A valoração da beleza cênica da paisagem do bioma pampa do Rio Grande do Sul: proposição conceitual e metodológica. 2014. 251f. Tese (Doutorado em Geografia), Universidade Federal do Rio Grande do Sul, Porto Alegre, 2014.

VILWOCK, J. A.; TOMAZELLI, L. J. Planície Costeira do Rio Grande do Sul: gênese e paisagem atual. In: BECKER, F. G.; RAMOS, R. A.; MOURA, L. de AZ. Biodiversidade: Regiões da Lagoa do Casamento e dos Butiazais de Tapes, Planície Costeira do Rio Grande do Sul. Brasília: MMA, 2007. p. 20-33.

WYLIE, J. Landscape and phenomenology. In: HOWARD, P.; THOMPSON, I.; WATERTON, E. (Org.). Handbook of Landscape Studies. London: Routledge, 2014. p. 5465.

YÁZIGI, E. A importância da paisagem. In: YÁZIGI, E. (Org.). Turismo e paisagem. São Paulo: Contexto, 2002. p. 11-28. 